\title{
Voces de origen mapuche en la obra del cronista chileno Alonso de Ovalle y su pervivencia en el español actual
}

\author{
Beatriz Gómez-Pablos ${ }^{1}$ \\ Universidad Comenius de Bratislava, Eslovaquia
}

\begin{abstract}
Resumen
El presente trabajo analiza las voces de origen mapuche en la Histórica Relación del Reino de Chile (1646), del cronista chileno Alonso de Ovalle. Centramos nuestra atención en la supervivencia de dichas voces en el español actual. Para ello hemos consultado tres obras lexicográficas publicadas en los últimos ocho años: el Diccionario de americanismos (2010), el Diccionario usual del español de Chile (2010) y el Diccionario de la Lengua Española (2014) de la Real Academia Española. Aunque Ovalle emplea otros indoamericanismos, aspecto que también tratamos, la mayor parte son mapuchismos y quechuismos. Este estudio desea contribuir a paliar una laguna presente en las investigaciones lingüísticas sobre la crónica de Ovalle.

Palabras clave: mapuchismos, Alonso de Ovalle, Histórica Relación del Reino de Chile, americanismos.
\end{abstract}

1 Para correspondencia, dirigirse a: Beatriz Gómez-Pablos, gomezpablos@fedu.uniba. sk, Katedra románskych jazykov a literatúr, Pedagogická fakulta, University Comenius, Šoltésovej 4, 81301 Bratislava, Eslovaquia. 


\section{WORDS OF MAPUCHE ORIGIN IN THE WORK OF THE CHILEAN CHronicler Alonso de Ovalle and their SURVIVAl IN CURRENT SPANISCH}

Abstract

The present paper analyzes the words of Mapuche language used in the Histórica Relación del Reino de Chile (1646), a work of the Chilean Alonso de Ovalle. We focus our attention on the survival of these words in current Spanish. For this purpose three lexicographic works published in the last eight years have been consulted: the Diccionario de americanismos (2010), the Spanish Diccionario usual del español de Chile (2010) and the Diccionario de la Lengua Española (2014). Although Ovalle employs other IndoAmericanisms, an aspect that we also deal with, most are words of Mapuche and Quechua. This study aims to contribute to alleviate a gap present in linguistic research on the Ovalle's chronicle.

Keywords: mapuchisms, Alonso de Ovalle, Histórica Relación del Reino de Chile, americanisms.

Recibido: 19/08/17

Aceptado: 30/04/18

\section{INTRODUCCIÓN}

La obra de Alonso de Ovalle, la Histórica Relación del Reino de Chile y de las misiones y ministerios que ejercita en él la Compañía de Jesús (Roma, 1646), constituye para algunos estudiosos chilenos "la obra más valiosa de nuestra literatura colonial" (Bunster 1969: 7) o, con palabras similares, "la obra cumbre de la literatura chilena del siglo XVII" (Latcham 1955: 857). Sin embargo, sorprende que se le haya prestado tan escasa atención si la comparamos con la de autores contemporáneos en el virreinato de Perú, como puede ser Garcilaso de la Vega el Inca, o en el virreinato de Nueva España, como es el caso de sor Juana Inés de la Cruz. Aunque no deseamos equiparar a estos tres autores, simplemente pensamos que el relieve de Ovalle no se refleja en la bibliografía existente. Casi todos los autores se 
limitan a presentar la biografía del cronista ${ }^{2}$ y a describir a grandes rasgos el contenido de la obra, extrayendo estas informaciones directamente de la Histórica Relación del Reino de Chile 3 . Queremos, por eso, recuperar una obra caída en el olvido y analizar en ella un aspecto lingüístico, a saber, la presencia de las voces mapuches. Como señala Sánchez, "se ha sostenido que el léxico mapuche solo ocurre en el español oral, coloquial e, incluso, vulgar; ello no es así, pues [...] se registra desde antiguo en las crónicas (2010: 151-152); y la de Ovalle es buena prueba de ello.

Los académicos del siglo XVIII no solo mencionan la crónica del jesuita en las listas de autoridades que preceden a la primera obra lexicográfica de la Real Academia Española de la Lengua, sino que hacen uso generoso de ella al citarla en los seis tomos que la componen. Este hecho no ha pasado desapercibido a los investigadores ${ }^{5}$ chilenos. Como demuestra Rojo (2014,

2 Ofrecemos un breve resumen: Hijo de padres españoles, nació en Santiago de Chile en 1601. Estudió con los jesuitas en su ciudad natal y poco después en Córdoba de Tucumán. En 1618 ingresó en la Compañía de Jesús, donde desempeñó diversos cargos (rector del Colegio de San Francisco Javier y procurador de la Provincia de Chile, entre otros). En 1642 viajó a Roma, donde redactó, publicó y tradujo al italiano la Histórica Relación del Reino de Chile. En 1650 emprendió el viaje de regreso a América, después de una breve parada en España, desde donde le acompañaron dieciséis jesuitas para el refuerzo de las misiones. Sin embargo, una fuerte fiebre le causó la muerte en Lima en 1651 e impidió que el jesuita llegara a Santiago de Chile.

3 Ovalle explica en el Prólogo el contenido de los ocho libros de que consta: "En el primer y segundo libros, la naturaleza y propiedades de aquella tierra; en el tercero, de sus habitadores; en el cuarto y quinto, la entrada de los españoles y su conquista. En el sexto varios sucesos de la guerra, que ha ocasionado la valerosa resistencia que han hecho los araucanos a los españoles; en el séptimo los medios de paz que intentó el padre Luis de Valdivia, de la compañía de Jesús, para facilitar la predicación del santo Evangelio, y la muerte de sus dichosos compañeros; y en el último, que es el más largo de todos, el mundo que hubo de plantar la fe y los progresos que ha hecho y hace, particularmente por medio de las misiones y ministerios de nuestra Compañía". La obra se inserta, por tanto, en el tradicional esquema de las historias naturales y morales de las Indias.

4 Reflejo de esto son las pocas ediciones que han visto la luz en castellano. La obra tampoco se vertió a muchas lenguas; además de la traducción italiana, solo tenemos noticia de una versión al inglés de los cinco primeros capítulos, publicados en Londres en 1703 para la colección Voyages and travels con el título An historical relation of the kingdom of Chile, by Alonso de Ovalle. Translated out of Spanish, printed for A. and J. Churchill.Fuera de esto, no conocemos otras traducciones.

5 Lira (1944), Bunster (1969), Latcham (1955), Hanisch (1976), Vial (2009), entre otros. Bunster, aunque se centra en aspectos históricos y no entra en el análisis de cuestiones filológicas, pues no es su objetivo, comenta que Ovalle "llegó a manejarlo [el lenguaje] con tal propiedad y elegancia, que el Diccionario de la Academia Española, cuya primera edición se conoce como Diccionario de Autoridades, [...] incluyó su nombre entre los doscientos setenta y un autores seleccionados" (1969: 14). 
Apéndice 3), Ovalle se encuentra entre los quince primeros más citados en el Diccionario de Autoridades (1726-1739), por encima de Mateo Alemán, Góngora, Calderón y Gracián, y por debajo de Quevedo, Cervantes o Lope, entre otros. El buscador electrónico de la RAE muestra 994 citas bajo OV. y 6 bajo OVALL. ${ }^{6}$; que se distribuyen en la obra de la siguiente manera: tomo I (A-B) 440; tomo II (C) 173; tomo III (D-F) 153; tomo IV (G-Ñ) 142; tomo V (O-R) 63; tomo VI (S-Z) 29.

De los 103 indoamericanismos presentes en la Histórica Relación del Reino de Chile, 30 de ellos figuran en el Diccionario de Autoridades. No obstante, el jesuita solo autoriza siete: aguacate, ají, cacicazgo, caoba, chacra, chicha y chilacayote. En dos casos es el único autor que autoriza las voces (aji y chilacayote), mientras que en los demás aparece junto a Lope de Vega (aguacate), Acosta (chicha) y la Recopilación de las Leyes de Indias (cacicazgo, caoba, chacra). Las 23 restantes voces que coinciden con Autoridades son: anona, cacique, canoa, cocobolo, dante, embijado, empacarse, guanábana (s.v. anona), guanaco (s.v. paco), guayacán (s.v. palo santo), macana, maiz, mate, ojota, mico, papa, piragua, quipo, tambo, tiburón, topo, tucán y vicuña. Algunas de ellas carecen de cita de autoridad, que con facilidad podría haber proporcionado el cronista chileno.

Es cierto que los indoamericanismos en las crónicas de Indias han sido investigados con frecuencia por numerosos lingüistas y son abundantes las publicaciones que extraen y analizan exhaustivamente las voces contenidas en dichas obras. No obstante, al tratarse en muchos casos de palabras que se han perdido, que estaban mal documentadas o que han alcanzado un uso geográfico reducido, la mayoría de los estudios se ocupan de ellas desde un punto de vista histórico sin establecer una relación con la actualidad. De ahí que hayamos querido centrarnos en este último aspecto. Para ello, hemos hecho un vaciado de las voces mapuches ${ }^{7}$ que emplea Alonso de Ovalle en su crónica y hemos consultado a continuación tres obras lexicográficas recientes con el fin de averiguar su uso actual.

\footnotetext{
6 El recuento de Bunster supera las 1.000 citas: "Mientras duró nuestro estudio, se tuvo a la vista la primera edición de esa monumental obra -seis volúmenes-y revisándola palabra por palabra, se comprobó que en mil cuatro ocasiones, correspondientes a otras tantas voces (y a veces giros), el Padre Alonso de Ovalle es citado como autoridad del idioma. [...] En muchos casos, en trescientos y diez y seis, él figura como única autoridad para confirmar el recto uso de una voz" (1969: 14).

$7 \quad$ Empleamos aquí mapuche y mapudungún como sinónimos.
} 


\section{VOCES MAPUCHES EN LA HISTÓRICA RELACIÓN}

Alonso de Ovalle empleó para la redacción de su crónica algunas obras que cita en la Histórica Relación. Entre ellas destacan las Décadas de Antonio de Herrera, la Conquista de México de López de Gómara, el Nuevo descubrimiento del gran río Amazonas de Cristóbal de Acuña y los Comentarios Reales del Inca Garcilaso de la Vega ${ }^{8}$. Utilizó además las

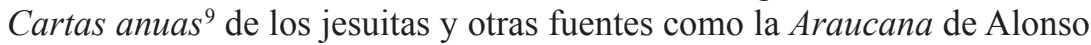
de Ercilla, la Historia del descubrimiento y conquista del Perú de Agustín de Zárate o la Araucana manuscrita de Hernando Álvarez de Toledo. Como señala Bunster, "en algunos capítulos, sigue a determinados autores al pie de la letra -sobre todo a Herrera, a Álvarez de Toledo y a Ercilla, por ejemplo-; y, como parecía ser costumbre en aquella época, suele incorporar a su texto, casi sin variantes y sin advertir su procedencia, pasajes enteros de otros escritores" (1969: 9). De esto podemos deducir que algunos de los indoamericanismos que emplea el escritor chileno se deben a un simple traspase de textos. Por otro lado, no descartamos que el contacto directo con los indígenas en las misiones jesuíticas y el estudio de sus lenguas, tan común en esa orden, le permitiera el conocimiento de numerosas palabras de origen quechua y mapuche. Ovalle debió conocer de primera mano la célebre obra del padre Luis de Valdivia ${ }^{10}$, la cual cita en diversos pasajes. Este religioso había publicado un Arte y gramática general de la lengua que corre en todo el Reino de Chile (Lima, 1606), seguido de un Vocabulario de la lengua de Chile, de una Doctrina christiana y de un Confesionario breve. Un año más tarde, en 1607, imprimía en Lima su Doctrina christiana y Catecismo en lengua Alletiac, que corre en la ciudad de San Juan de la Frontera, con un Confesionario, Arte y Vocabulario breves.

\footnotetext{
8 "A quien en estas materias que pertenecen al Perú debemos más crédito que a otros, por haber nacido en él y sabido la lengua de los indios y haber podido por esto hacer más exacto escrutinio de todo" (VIII, 1).

9 Precisamente estas Cartas anuas, llegadas de Chile también durante su estancia en Roma, le permitieron incorporar noticias actuales a su Histórica Relación.

10 "Con ocasión de catequizar y hacer cristianos a unos indios que se llaman Guarpes (que son los que dijimos en su lugar, habitan en la tierra de Cuyo, que está de la otra banda de la cordillera) aprendió su lengua (que es totalmente distinta de la de Chile) y hizo gramática y vocabulario de ella y la imprimió con el de Chile, con que dejó allanado el camino a los nuestros para poder emplearse en la enseñanza y conversión de los indios" (VIII, 5).
} 
La Histórica Relación contiene un total de 36 mapuchismos ${ }^{11}$. Hemos dejado fuera de consideración los nombres de los diferentes pueblos (o naciones) indígenas y los topónimos. Junto a cada voz recogemos una breve cita $^{12}$ extraída de la crónica y debajo de ella ofrecemos las definiciones de la trigésima edición del Diccionario de la lengua española (DRAE-2014), del Diccionario de americanismos (DAm-2010) y del Diccionario usual del español de Chile (DUECh-2010). También consultamos el Diccionario de peruanismos (DP-2009) cuando no las encontramos en esos; sin embargo, en contra de nuestras expectativas, no hemos hallado en él ninguno de los mapuchismos de la crónica del jesuita.

Listamos a continuación las voces mapuches. Al final de algunas de ellas añadimos también un breve comentario:

(1) Carén: Consérvase todo el año verde, con la yerba que nace en ella a manera de menudo trébol, a quien los naturales llaman carén, y es regalada de comer $(I, 12)$.

[a] No se recoge en DRAE-2014, DAm-2010, DUECh-2010.

Comentario: La voz procede del mapuche karv we, que significa 'lugar verde'. En Chile se conoce una laguna en la provincia de Santiago con este nombre, así como un embalse en la provincia de Melipilla. El Diccionario geográfico-histórico de las Indias Occidentales (1786-89), de Antonio de Alcedo, recoge esta palabra: "Valle o prado del Reyno de Chile, célebre por su amenidad, hermosura y extensión de 5 leguas de largo, como por una fuente que hay en él de agua muy delicada y saludable, la qual se resume en el terreno poroso, que pisando con fuerza tiembla: en él se conserva todo el año la yerba verde, que es muy menuda, semejante al trébol, a quien los naturales llaman carén, que es de muy agradable gusto, y da el nombre al valle".

(2) Chavalongo: en una pestecilla que corrió una temporada, de chavalongo, de que murieron muchos indios (VIII, 22).

[a] No se recoge en DRAE-2014 ni en DUECh-2010.

11 Sánchez (2010: 152) señala que esta voz no aparece en el DRAE-2001. Tampoco figura en el DRAE-2014. Compartimos con el lingüista chileno la propuesta de emplear este término para definir el "préstamo lingüístico de origen mapuche introducido en el español" o el "vocablo o giro de origen mapuche empleado al hablar o escribir en español" (152-153).

12 En algunos casos hemos considerado necesario añadir alguna más. 
[b] DAm-2010: 1. m. Ar. obsol. Fiebre tifoidea. pop+cult> espon.

Comentario: Se trata de una enfermedad acompañada de dolor de cabeza, fiebre y delirios. Góngora Marmolejo la recoge en su Historia de Chile (15761850): "Juntóseles otro gran mal con este, que entrando la primavera les dio en general una enfermedad de pestilencia que ellos llamaban chavalongo, que en nuestra lengua quiere decir dolor de cabeza" (en Alvar Ezquerra 1997, s.v. chavalongo).

(3) Choñi: porque usan traer todo el brazo descubierto y el choñi, que es lo que les sirve de capa (II, 1); a la capa llaman choñi (III, 4).

[a] No se recoge en DRAE-2014, DAm-2010, DUECh-2010.

Comentario: Lozano (1754) ${ }^{13}$ describe también esta pieza de vestir en relación con el macún: "sobre el Macún, cuando salen de casa, usan del Choni, que es su capa, de la hechura de una sobremesa" (II, 4).

(4) Cona: Aquí me tenéis, conas (llaman así a la gente de guerra) (VII, 2); Capitanes y conas (que son los soldados) (VII, 3).

[a] No se recoge en DRAE-2014, DAm-2010, DUECh-2010.

Comentario: Valdivia (1684) define cona como 'soldado' y yana como 'criado'. Febrés (1846), en su Diccionario hispano chileno, define cona como 'mocetón: esforzado y valiente' y yana como 'indios ladinos, criados entre españoles'. Pensamos, que cona y yanacona ${ }^{14}$ podrían estar emparentadas, aunque tanto el DRAE-2014 ${ }^{15}$ como el DAm-2010 ${ }^{16}$ coinciden en suscribir origen quechua a yanacona. Es cierto, como afirma Sánchez, que "algunas voces mapuches proceden del quechua, pero fueron incorporadas en el

13 El título de la obra de Lozano, Historia de la Compañía de Jesús en la provincia del Paraguay, a primera vista, despista pero al leer sus páginas se comprueba que muchas describen aspectos que se refieren a Chile. Este jesuita cita con frecuencia la crónica de Ovalle, de la que copia algunos pasajes.

14 "Eran los yanaconas, entre los indios, cierto linaje de gente sujeta a perpetua servidumbre [...]. Lo que en Chile significa ahora el nombre de yanacona no es otra cosa que los indios que no son de encomienda" (IV, 16); "yanaconas, que son los indios de servicio" (VIII, 15).

15 'Dicho de un indio: Que estaba al servicio personal de los españoles en algunos países de la América meridional'.

16 'Indio que es aparcero en el cultivo de una tierra'. 
mapuche seguramente en tiempos precolombinos y, por ello, los hablantes ya no las sienten como extranjeras. Por consiguiente, forman parte de su acervo léxico permanente" (2010: 157). La cuestión del parentesco queda, por tanto, irresuelta.

(5) Culén: La segunda yerba sea la que llamamos albahaquilla, y los indios culén $(I, 2)$.

[a] DRAE-2014: De or. mapuche. 1. m. albahaquilla de Chile. 1. f. Arbusto leguminoso, indígena de Chile, cuyas hojas, flores y tallo se toman en infusión como medicamento contra las enfermedades del estómago.

[b] DAm-2010: I. 1. m. Pe, Ch, Ar. Arbusto de hasta 3 metros de altura, hojas de tres foliolos lanceolados, flores azules y una vaina alargada como fruto; la infusión de sus hojas y flores tiene propiedades digestivas (Fabaceae; Psoralea glandulosa).

[c] DUECh-2010: (De origen mapuche). $\mathrm{m}$. Arbusto de hasta $5 \mathrm{~m}$ de altura, tronco café oscuro, ramas erectas, flores dispuestas en racimo, hojas de agradable olor y sus frutos son legumbres. La infusión de sus hojas, flores y tallo se toma como medicamento contra las enfermedades del estómago.

(6) Culteu: Otro género de pájaros que llaman los indios culteu [...], son estos tan grandes como gaviotas, pero de muy largas zancas, y en los encuentros de las alas les proveyó la naturaleza de unas púas como almaradas para defenderse de sus contrarios, y los españoles los llaman frailes a estos pájaros, o porque nunca anda uno sólo sin compañero [...] o porque el color y variedad de las plumas es de tal disposición que traen capa y capilla $(I, 19)$.

[a] DRAE-2014: queltehue. De or. mapuche. 1. m. Ave zancuda de Chile parecida al frailecillo, que habita en los campos húmedos y que domesticada se tiene en los jardines porque destruye los insectos nocivos.

[b] DAm-2010: queltehue: $\sim$ de la puna. m. Ch: $N E$. leque leque.

Bajo leque: (Del aim. liqiliqi). m. Pe: $S E, B o, C h: N E$. Ave de hasta $32 \mathrm{~cm}$ de longitud, de color gris en casi todo el cuerpo excepto el abdomen y la cola, que son blancos; pico negruzco con base amarillenta y patas rosadas. (Charadriidae; Vanellus resplendens). liclish; queltehue de la puna.

[c] DUECh-2010: (De origen mapuche). m. Ave que habita desde Antofagasta hasta Tierra del Fuego, frecuentemente en lugares húmedos y orillas de tranques y lagunas. Su frente, garganta y pecho son de color negro intenso, contrastando fuertemente con el abdomen blanco. 
Comentario: Su nombre científico es Vanellus chilensis. Hoy se conoce en Chile más comúnmente por traile o treile.

(7) Degus: Son también propios de aquella tierra unos conejitos, que los indios llaman degus, de que gustan mucho en sus comidas (I, 21).

[a] No se recoge en DRAE-2014, DAm-2010, DUECh-2010.

Comentario: El degú (del mapuche dewü, que significa 'ratón') es un roedor chileno (Octodon degus). Mide entre 25 y $35 \mathrm{~cm}$, tiene una cola de 18 centímetros, que termina en pincel, y habita desde la zona de Huasco (III Región) a Rapel (VI Región). Se vende como mascota.

(8) Huingán: Otra [bebida] hacen del que llaman huingán, y los españoles molle (I, 22).

[a] DRAE-2014: 1. m. Arbusto chileno, de la familia de las anacardiáceas, de flores blancas y pequeñas en racimos axilares, y frutos negruzcos, de unos cuatro milímetros de diámetro.

[b] DAm-2010: I. 1. m. Ch, Ar: S. Arbusto de hasta 2,5 m de altura, de flores blancas y pequeñas en racimos axilares, y frutos de color violeta oscuro; sus frutos se usan para hacer bebidas alcohólicas y también como desinfectante de heridas. (Anacardiaceae; Schinus polygamus).

[c] DUECh-2010: (De origen mapuche). M. Arbusto que crece en las laderas, ramificado casi desde la base, de tronco tortuoso y ramas delgadas terminadas en espinas; las flores, de color crema, están dispuestas en racimos y el fruto negruzco es comestible. Su madera se utiliza como leña y la resina como purgante.

(9) Leupes: Tuestan primero el maíz en sus leupes, que son como unas grandes albornías de barro (III, 3).

[a] No se recoge en DRAE-2014, DAm-2010, DUECh-2010.

Comentario: Valdivia (1684) recoge leupe: 'cazuela o callana'; lo mismo que Febrés, (1846) con otra grafía leghpe, o leupe: 'tiesto de tostar'.

(10) Lloicas [loica]: Los pájaros que llaman los indios lloicas [...]. Llaman los Españoles estos pájaros pechicolorados, porque no ay grana ni escarlata, que llegue a la fineza del rojo de su pecho, las demás plumas del cuerpo y de las alas son pardas (I, 19). 
[a] DRAE-2014: Voz mapuche. 1. f. Pájaro chileno algo mayor que el estornino, al cual se parece en el pico, pies, cola y aun en el modo de vivir y alimentarse. El macho es de color gris oscuro, manchado de blanco, a excepción de la garganta y pecho, que son de color de escarlata. Se domestica con facilidad y es muy estimado por su canto dulce y melodioso.

[b] DAm-2010: (Voz mapuche). I. 1. f. Ch, $A r$. Pájaro de hasta $25 \mathrm{~cm}$ de longitud, de color pardo oscuro con una gran mancha colorada en el pecho. (Icteridae; Sturnella loyca).

[c] DUECh-2010: (De origen mapuche). f. Ave que habita en terrenos bajos y húmedos, de plumaje café pardo con una gran mancha roja en la parte delantera y una línea blanca sobre el ojo que llega hasta la nuca. Su canto es muy melodioso.

(11) Locos: Pertenecen también a este marisco en concha los que llaman locos (I, 16).

[a] DRAE-2014: Voz mapuche. 1. m. Chile. Molusco de carne comestible, pero dura, que se come guisado.

[b] DAm-2010: I. 1. Ch. chanque.

Bajo chanque: I. 1. m. Pe. Molusco gasterópodo marino de hasta $10 \mathrm{~cm}$, de concha gruesa, dura y calcárea, y cuerpo blando; su carne es muy apreciada (Muricidae; Concholepas concolepas).

[c] DUECh-2010: (De origen mapuche). m. Molusco marino comestible que habita adherido a las rocas, de concha estriada café grisáceo y carne dura.

(12) Luche: Una yerba a manera de escarolas, que llaman luche, la cual se arranca de las peñas [...] y puesta a secar al sol, se hacen unos panes grandes que se estiman por gran regalo la tierra adentro $(I, 16)$.

[a] DRAE-2014: Voz mapuche. 1. m. Alga marina comestible de Chile.

[b] DAm-2010: II. 1. Ch. Alga de hasta $15 \mathrm{~cm}$ de longitud, de tallo verde laminar, foliáceo y lobulado; es comestible. (Ulvaceae; Ulva rígida). 2. Ch. Alga de hasta $15 \mathrm{~cm}$ de longitud, de tallo de color pardo amarillento a púrpura, de bordes lisos y ondulados; es comestible. (Bangiaceae; Porphyra columbina).

[c] DUECh-2010: (De origen mapuche). m. Alga marina que puede corresponder a una de sus variedades. Una es un alga verde que vive en la zona media de mareas sobre rocas, abundante a lo largo de todo Chile. La otra especie es un alga roja, a veces de café, que vive hacia el límite superior de la zona de mareas. Ambas tienen forma similar a una hoja de lechuga, con bordes ondulados, y son comestibles. 
(13) Machis: Conocidas, solamente de los indios que llaman machis, que son sus médicos (I, 2); hacer oficio de machi (que es curandera, y a las veces, hechicera) (VIII, 19).

[a] DRAE-2014: Voz mapuche. 1. m. y f. Chile. En la cultura mapuche, curandero de oficio, especialmente cuando es mujer.

[b] DAm-2010: (Voz mapuche). I. 1. m-f. Ar. En la cultura araucana o mapuche, curandero, especialmente cuando es mujer. 2. Ch. En la cultura araucana o mapuche, curandero con poderes mágicos.

[c] DUECh-2010: (De origen mapuche). m-f. Persona, generalmente mujer, que ejerce la autoridad religiosa entre los mapuches, y usualmente practica rituales de sanación.

(14) Macuñ: La ropa que visten los indios, que son el macuñ, a manera de almilla sin mangas, porque usan traer todo el brazo descubierto (II, 1); El cuerpo lo visten con la que llamamos camiseta y ellos macuñ (III, 4).

[a] DRAE-2014: No se recoge.

[b] DAm-2010: (Del map. makuñ). I. 1. m. Ch: S. Poncho masculino.

[c] DUECh-2010: (De origen mapuche). 1. m. En la mitología de Chiloé, prenda tejida que cubre el torso y los brazos, empleada por los brujos y que les permite volar. 2. m. Manta usada por hombres.

(15) Madi: Muy buen aceite, que se hace de una semilla que se llama madi y es de muy buen sabor (I, 22).

[a] No se recoge en DRAE-2014, DAm-2010, DUECh-2010.

Comentario: Febrés (1846) recoge madi: 'semilla como melosa, de que se saca aceite'.

(16) Malal: con todo un lienzo del malal (VIII, 22).

[a] No se recoge en DRAE-2014, DAm-2010, DUECh-2010.

(17) Mallcagües: Hay otros muchos de varios colores de que sacan los indios las plumas para sus mallcagües, que son un género de adorno que hacen para la cabeza a manera de guirnaldas, no de flores, sino de varios y finísimos colores de lanas, en que fijan unos penachos muy altos, de que usan sólo en los bailes y regocijos (I, 19). 
[a] No se registra en DRAE-2014, DAm-2010, DUECh-2010.

Comentario: Valdivia (1684) recoge mallcautuhue: 'lo que se ponen los Indios en la cabeza'.

(18) Malocas: Las malocas y encuentros que se ofrecen continuamente con el enemigo (V, 12); Malocas (que es lo mesmo que correrías) (VI, 15).

[a] DRAE-2014: Del mapuche malocán. 1. f. Arg., Chile y Ur. Invasión de hombres blancos en tierra de indígenas, con pillaje y exterminio. 2. f. Arg. $y$ Chile. Ataque inesperado de indígenas contra poblaciones de españoles o de otros indígenas.

[b] DAm-2010: No se recoge.

[c] DUECh-2010: (De origen mapuche). Remite a malón. 1. m. Incursión guerrera sorpresiva y fugaz que realizaban los mapuches en territorio de los conquistadores españoles para obtener recursos. hist.

Comentario: El DUECh-2010 la considera un término histórico. Según la definición de DRAE-2014 podría entenderse que ese tipo de invasiones siguen sucediendo.

(19) Maloquear (de maloca): Entraban en tropas a maloquear a nuestros indios amigos (VII, 7); Volvieron los dos campos a maloquearles (VII, $11)$.

[a] DRAE-2014: De maloca. 1. intr. Dicho de los indios: Hacer correrías. [b] No se recoge en DAm-2010 ni en DUECh-2010.

(20) Mañegues: Otro género de marisco se llama mañegues (I, 16).

[a] No se recoge en DRAE-2014, DAm-2010, DUECh-2010.

(21) Maques [maqui]: Otros árboles se llaman maques y son muy hermosos y frescos, y sirven sus hojas [...] contra quemaduras y otros accidentes que nacen del calor. Es su fruta negra, a manera de la de arrayán, y muy sabrosa [...], tiñe la boca y manos cuando se come (I, 22).

[a] DRAE-2014: Voz mapuche. 1. m. Arbusto chileno, de la familia de las liliáceas, de unos tres metros de altura, con hojas aovadas y lanceoladas, flores axilares en racimo, y fruto redondo, de unos cinco milímetros de diámetro, dulce y un poco astringente, que se emplea en confituras y helados. Los indios preparan también con él una especie de chicha. 
[b] DAm-2010: I. 1. m. Ch., Ar. Arbusto de hasta $3 \mathrm{~m}$ de altura. Con hojas aovadas, flores axilares en racimo, y fruto redondo, dulce y un poco astringente, que se emplea en confituras y helados; también se prepara con él una especie de chicha. (Liliaceae; Aristotelia chilensis).

[c] DUECh-2010: (De origen mapuche). m. Arbusto que crece en lugares húmedos, de tronco delgado, flores amarillentas dispuestas en racimos y un fruto negro y redondo con el que se fabrica chicha (bebida alcohólica).

(22) Pataguas: Las tablas de pataguas son más ordinarias y de menos estima (I, 22).

[a] DRAE-2014: De or. mapuche. 1. f. Árbol de Chile de la familia de las tiliáceas, con tronco recto y liso de seis a ocho metros de altura, copa frondosa, hojas alternas, partidas en tres lóbulos agudos, flores blancas axilares, fruto esférico capsular, y madera blanca, ligera y útil para carpintería.

[b] DAm-2010: No se recoge.

[c] DUECh-2010: f. Árbol que crece desde el río Aconcagua hasta Concepción, en ambas cordilleras, y que alcanza una altura de hasta $10 \mathrm{~m}$; tiene corteza color gris con hendiduras, hojas con borde aserrado, flores blancas y fruto capsular. Los taninos de la corteza se utilizan en curtiembres y la madera en mueblería.

(23) Peucus [peuco]: Muy semejantes son a estos pájaros [gallinazos] otros que llaman peucus, no sólo en el color, figura y grandeza (I, 18).

[a] DRAE-2014: Del mapuche peuco. 1. m. Chile. Ave de rapiña diurna, semejante al gavilán.

[b] DAm-2010: I. 1. m. Ch. Ave rapaz diurna de hasta $50 \mathrm{~cm}$ de longitud, de cabeza, dorso y lomo negros, a veces con plumas bordeadas de rojo, garganta blanquecina con líneas longitudinales negras, cuello, pecho y abdomen negruzcos, cola negra con borde terminal blanco, pico azulado oscuro con cera amarilla, patas amarillas y uñas grandes negras. (Accipitridae; Parabuteo unicinctus).

[c] DUECh-2010: (De origen mapuche). $m$. Ave de rapiña diurna que habita en lomas y campos abiertos, de plumaje negro con manchones blancos en el abdomen; es muy agresivo y de vuelo rápido.

Comentario: la definición de DRAE-2001 es más extensa: 'Ave de rapiña, diurna, semejante al gavilán, aunque el color varía según la edad y el sexo del animal, dominando el gris ceniciento. Se alimenta de pájaros, palomas y aun de pollos de otras aves, y a falta de ellos, come lagartijas y otros reptiles'. 
(24) Peugu: Otros árboles hay fructíferos de los silvestres, que nacen en los campos, y se llaman peugu. Tienen la fruta colorada, un poco más larguita y ovada que la avellana, la cual comen los indios (I, 22).

[a] No se recoge en DRAE-2014, DAm-2010, DUECh-2010.

Comentario: Sánchez Cabeza (2010: 181) identifica esta voz con peumo, que sí se recoge en nuestros tres diccionarios:

[a] DRAE-2014: peumo. Del mapuche peyu.1. m. Chile. Árbol de la familia de las lauráceas, de hoja aovada y siempre verde, y fruto ovalado y rojizo que contiene una pulpa blanca y mantecosa comestible.

[b] DAm-2010: peumo. I. 1. m. Ch. Árbol de hasta 25 m de altura, de tronco recto, corteza lisa poco agrietada, ramas centrales gruesas ascendentes, hojas perennes, aromáticas, simples, alternas y opuestas, flores en panojas o racimos densos, de color amarillo verdoso. (Lauraceae; Cryptocarya alba). (belloto). 2. Ch. Fruto del peumo, de color rojo; es comestible. (belloto).

[c] DUECh-2010: (De origen mapuche). m. Árbol que crece en quebradas y lugares húmedos, de corteza agrietada color gris, hojas aromáticas y que tiene por fruto una baya rojiza comestible. Su madera es resistente al agua, por lo que se utiliza en la fabricación de zapatos y herramientas.

(25) Pínguedas: Otros hay pequeñitos que llaman pínguedas, cuyo cuerpecito será poco más de una almendra; estos se sustentan de las flores, y para poder comer la miel que éstas crían dentro de sus hojas les dio la naturaleza un pico que, cuando está cerrado, casi no se diferencia de una aguja de coser; a esta causa comen siempre volando de flor en flor $(\mathrm{I}, 19)$.

[a] No se recoge en DRAE-2014, DAm-2010, DUECh-2010.

Comentario: Rosales (1674) habla del picaflor y dice: "Los Indios de Chile la llaman Pingueda. El cuerpesillo apenas iguala con la zigarra. Está bien vestida de sutiles plumas, verdes, naranjadas, doradas, y de otros varios, hermosos y lucidos colores. El pico largo, y tan delgado como una aguja de coser, con el qual recoje el rocío, y jugo de las flores para su alimento" (II, 23). Valdivia (1684) recoge piñuda y lo define como 'tominejo, ave', mientras que en el Diccionario de Febrés (1846) no aparece.

La voz aparece en varias páginas de internet que describen aves chilenas y casi siempre con indicación sobre el origen mapuche de la palabra. 
(26) Quelu [quilo]: Acuérdome del quelu, que es una fruta muy dulce, pequeñita, entre colorada y amarilla, de que hacen una bebida demasiadamente dulce (I, 22).

[a] DRAE-2014: 3. Del mapuche quelu 'colorado'. 1. m. Chile. Arbusto de la familia de las poligonáceas, lampiño, de ramos flexuosos y trepadores, hojas oblongas algo asaeteadas, flores axilares o aglomeradas en racimo, y fruto azucarado, comestible, del cual se hace una chicha. 2. m. Chile. Fruto del quilo.

[b] DAm-2010: No se recoge.

[c] DUECh-2010: 2. m. Fruto del quilo, correspondiente a una nuez pequeña y carnosa de sabor dulce que se usa en la preparación de un tipo de chicha.

(27) Quinchamalí: La famosa yerba que llaman quinchamalí, la cual no se levanta del suelo más de un jeme, y sus ramas se esparcen y recogen a manera de ramillete y rematan en la punta cada una con una flor del color y hechura del azafrán que se llama romí (I, 2).

[a] DRAE-2014: Del mapuche quinchamallín. 1. m. Arg. y Chile. Planta medicinal, de la familia de las santaláceas, que mide entre 10 y $20 \mathrm{~cm}$ de altura, con hojas alternas, lanceoladas, y flores amarillas terminales, dispuestas en espigas cortas apretadas.

[b] DAm-2010: I. 1. m. Ch, Ar: SO. Planta de hasta $20 \mathrm{~cm}$ de altura, con hojas alternas y lanceoladas y flores amarillas terminales, dispuestas en espigas cortas apretadas; tiene propiedades medicinales. (Santalaceae; Quinchamalium chilense).

[c] DUECh-2010: (De origen mapuche). m. Hierba que crece en laderas asoleadas, de tallo ramificado, pequeñas hojas alargadas y abundantes flores amarillas dispuestas en espigas. En medicina popular se usa para curar heridas.

(28) Reguas [rehue]: Sus diez parcialidades, o reguas, con sus Caciques y Capitanes, y muchos Indios, cargados de sus presentes, sin que de esto se eximiese ninguna Regua (VII, 18); Con él toda aquella regua (llaman así a una parcialidad) (VII, 5).

[a] No se recoge en DRAE-2014 ni en DAm-2010.

[b] DUECh-2010: rehue: (De origen mapuche). $\mathrm{m}$. Tronco tallado dispuesto en forma vertical, que se emplea como elemento ritual en algunas ceremonias de los mapuches. 
Comentario: El rehue (de rewe) es un altar sagrado utilizado por los mapuches en las ceremonias. Se trata de un tronco escalonado clavado en la tierra. A veces la parte superior tiene representado un rostro humano. Por extensión, a veces se denomina rehue (o regua en las crónicas coloniales) a una pequeña agrupación de familias que ocupan un mismo territorio (véase Wikipedia $\left.r e h u e^{17}\right)$.

Vial (2009: 196 y 202) emplea esta voz en el sentido de 'tribu': "Ribera y su bando sostenían haber obtenido las paces de las tribus más violentas. Eran los rehues de Arahuco; los de Catiray, conocidos nuestros, y los pureninos"; "Luego tuvo el Padre un gesto audacísimo... pidió que lo recibieran los rehues de Catiray".

(29) Tacas: Un género muy regalado de marisco, que llaman tacas (I, 8); Otras especies hay de más pequeños, que llaman tacas $(I, 16)$.

[a] DRAE-2014: De or. mapuche. 1. f. Chile. Marisco comestible, de concha casi redonda, estriada, blanca con manchas violadas y amarillas.

[b] DAm-2010: I. 1. f. Ch. Almeja de forma oval redondeada, con estrías concéntricas y radiales de color crema con rayas color café y dibujos lineales o geométricos. (Veneridae; Protothaca thaca).

[c] DUECh-2010: No lo recoge.

(30) Taltales: Críanse también con gran abundancia los taltales o gallinazos, son estos casi tan grandes como patos, pero tienen mayores alas, son de color negro o pardo y voracísimos de carne en extremo (I, 18); Los demás cuerpos de los indios comidos de unos pajarotes que llamamos allá Gallinazos y taltales (VII, 6).

[a] No se recoge en DRAE-2014, DAm-2010, DUECh-2010.

Comentario: Bunster (1969: 65) afirma que se trata de una "voz mapuche que ya no se usa; era el nombre vulgar de los gallinazos, Athartes urubus". No hemos encontrado esta palabra en ningún diccionario, pero Taltal es el nombre de una ciudad y comuna del norte de Chile, en la II región de Antofagasta. En un folleto publicado por el Gobierno de Chile (Ministerio de Bienes Naturales) con el título de Taltal. Punta Tortolas. Historia y desierto junto al mar, se lee: "El nombre de la ciudad deriva de Thalthal, palabra 
mapuche que hace referencia a ave, buharro o gallinazo (Athartes Urubus), especie de cernícolo (ave falconiforme de pequeño tamaño), éste puede ser avistado en los roqueríos del borde costero"18 (2015: 10).

(31) Toques [toqui]: Llámanse toques, entre los indios, los más principales, a quien obedecen los otros en la guerra) (VI, 11); Toque (llaman así al capitán general) (VII, 9).

[a] DRAE-2014: 1. m. Chile. Entre los antiguos mapuches, jefe del Estado en tiempo de guerra.

[b] DAm-2010: No se recoge.

[c] DUECh-2010: (De origen mapuche). m-f. Jefe de los mapuches durante un periodo de guerra.

(32) Toquis: los toquis que están clavados en el suelo [...] untando sus toquis (VIII, 16).

[a] No se recoge en DRAE-2014, DAm-2010, DUECh-2010.

Comentario: Se trata tanto en el caso de toque como de toqui de la misma palabra; en los documentos aparecen con frecuencia las dos grafías. Ninguno de nuestros tres diccionarios recoge la acepción de 'hacha'. El toki era un jefe mapuche en tiempo de guerra, cuya insignia de mando era un hacha de piedra, de modo que el término se aplica aquí por extensión.

(33) Ullpu [ulpo]: Desatan la harina con un poco de agua, que les sirve de comida haciéndola rala (y llaman ullpu), y de comida cuando está más espesa (y llaman rubul), echando dentro el ají y el pedazo de sal, o lamiéndola cuando comen la harina a secas (III, 3).

[a] DRAE-2014: 1. m. Chile. Especie de mazamorra hecha con harina tostada y agua fría.

[b] DAm-2010: (Del mapuche ulpu). I. 1. m. Ar: NO. Bebida refrescante hecha de agua endulzada con miel, que solía espesarse con harina de algarroba. 2. Ch. Papilla o puré hecho con harina tostada y agua fría.

[c] DUECh-2010: (De origen mapuche). $\mathrm{m}$. Brebaje preparado con harina tostada mezclada con agua o con leche.

18 Disponible en http://rutas.bienes.cl/wp-content/uploads/2015/01/35.pdf [Consulta: 2/10/2016] 
(34) Ulmenes: Cincuenta ulmenes (llámanse así las cabezas de las parcialidades) (VII, 2).

[a] No se recoge en DRAE-2014, DAm-2010, DUECh-2010.

Comentario: El ulmén es el jefe en tiempos de paz y es elegido para dirigir una tarea concreta, como por ejemplo, construir una casa o realizar la cosecha.

(35) Últeu [huilte]: Donde nace un tronco como la muñeca, que llaman últeu $(\mathrm{I}, 16)$.

[a] DRAE-2014: 1. m. Chile. Tallo o tronco del cochayuyo, principalmente cuando está creciendo y antes de ramificarse. Es comestible.

[b] DAm-2010: I. 1. m. Ch. Tallo o tronco del cochayuyo, principalmente cuando está creciendo y antes de ramificarse; es comestible.

[c] DUECh-2010: huilte remite a ulte (De origen mapuche). m. Tallo o raíz del cochayuyo (alga), de color verde, que suele utilizarse en la preparación de ensaladas y mariscales.

(36) Uñi: Hay un género de fruta de árboles [...] y la llaman uñi, y los castellanos dicen murtilla, es colorada y como una pequeña uva, mayor que garbanzos remojados: su hechura y color es como una granadita, su hollejo y sabor agradable como de uvas, sus granillos como los del higo, que no se sienten al comer; su complexión caliente y seca; de ella, se hace vino, que es mejor que todos los brebajes (I, 22) ${ }^{19}$.

[a] DRAE-2014: 1. m. Chile. Arbusto de la familia de las mirtáceas, con flores rojizas y por fruto una baya comestible.

[b] DAm-2010: I. 1. m. Ch: C, S. p. u. murtilla, arbusto.

[c] DUECh-2010: (De origen mapuche). $\mathrm{m}$. Arbusto que crece en lugares húmedos desde la zona central al extremo austral de Chile, de ramas erectas con flores blancas que cuelgan de ellas, y un fruto que es una baya ovalada color rojo oscuro. Con el fruto se preparan mermeladas, licores y repostería en general. 


\section{OTROS AMERICANISMOS PRESENTES EN LA OBRA}

Además de las voces mapuches, la crónica del jesuita chileno registra nahuatlismos (aguacate, camote, chilacayote, chile, pitahaya), voces de las lenguas antillanas (aji, anones, cacique, cacicazgo, canoa, caoba, embijado (de bija), guanábana, guayaba, guayacán, jagüeyes, macana ${ }^{20}$, maíz, mamey, manglares, papaya, piragua, pitahaya), alguna del cuna, del aimara, del cumanagoto y del tupí-guaraní (chicha, amauta, micos, tucán, respectivamente) y más de una treintena de quechuismos (aillo, apancora, camarico, chacra, chañal, choclo, choro, cochayuyo, cóndor, cumbe, cuy, empacarse (de paco), guanaco, icho, huaca, llanca, lúcuma, mate, molle, mote, ojota, pampa, papa, poroto, quipo, quiriquincho, runa, tambo, topo, vicuña, viracocha, yanacona, zapallo). Predominan, por tanto, las de origen mapuche y quechua.

Las palabras que Ovalle emplea con mayor frecuencia son: maiz, cacique y canoa; seguidas de chacra, chicha, maloca, pampa, regua y yanacona. El resto de las voces se registran generalmente una o dos veces. La Histórica Relación contiene también indoamericanismos cuya lengua de origen es incierta, como es el caso de cibil $^{21}$, cipizapote ${ }^{22}$, cocobolo, dante [danta], rubul, tacum y tiburón. Los 103 indoamericanismos (cuatro de ellos

20 El DUECh-2010 sostiene que el origen de macana es quechua.

21 No lo recoge ninguno de nuestros cuatro diccionarios (DRAE-2014, DAm-2010, DUECh-2010, DP-2009), pero sí aparece en otras crónicas de Indias, como por ejemplo en la Descripción Corographica del terreno, ríos, árboles y animales de las dilatadissimas Provincias del gran Chaco, Gualamba: y de los ritos, y costumbres de las innumerables naciones bárbaras, e infieles, que la habitan... (Córdoba [de Tucumán], 1733), de Pedro Lozano, donde se lee: "El Cibil es árbol muy grande, fortísimo especialmente en las quebradas, que tira siempre a buscar el sol. Su corteza es admirable para curtir" (apartado IV, sobre la Calidad de la Tierra del Chaco, árboles, y plantas, que produce).

22 Amado Alonso apunta que se trata de "una fruta americana que se llama zapotillo o chicozapote. Tirso la llama cipizapote (La villana de Vallecas). Nuestro llorado Pedro Henríquez Ureña me decía que el nombre hubo de aprenderlo Tirso en Santo Domingo, a principios del siglo XVII. Pero este caso apenas entra en nuestras series. Tanto lo de chico-zapote (cf. zapotillo) como lo de cipi-zapote son versiones castellanizadas del náhuatl tzictzápotl, análisis o etimologías populares apoyadas en chico o en cipi-zape" (1947: 11, n. 16). Mientras que, por su parte, Prieto García-Seco, refiriéndose al Diccionario de la lengua española (1917) de José Alemany y Bolufer, escribe: “Allí se registra la voz cipizapote, con la marca fest.[ivo] y con remisión a zapote. Se trata de una creación ocasional, una deformación léxica que solo se registra en la comedia de Tirso de Molina La villana de Vallecas" (2007: 132). Llama la atención que Ovalle recogiese esta extraña voz en su Histórica Relación. 
derivados: cacicazgo, embijado, empacarse y maloquear) contenidos en la crónica se distribuyen de la siguiente manera:

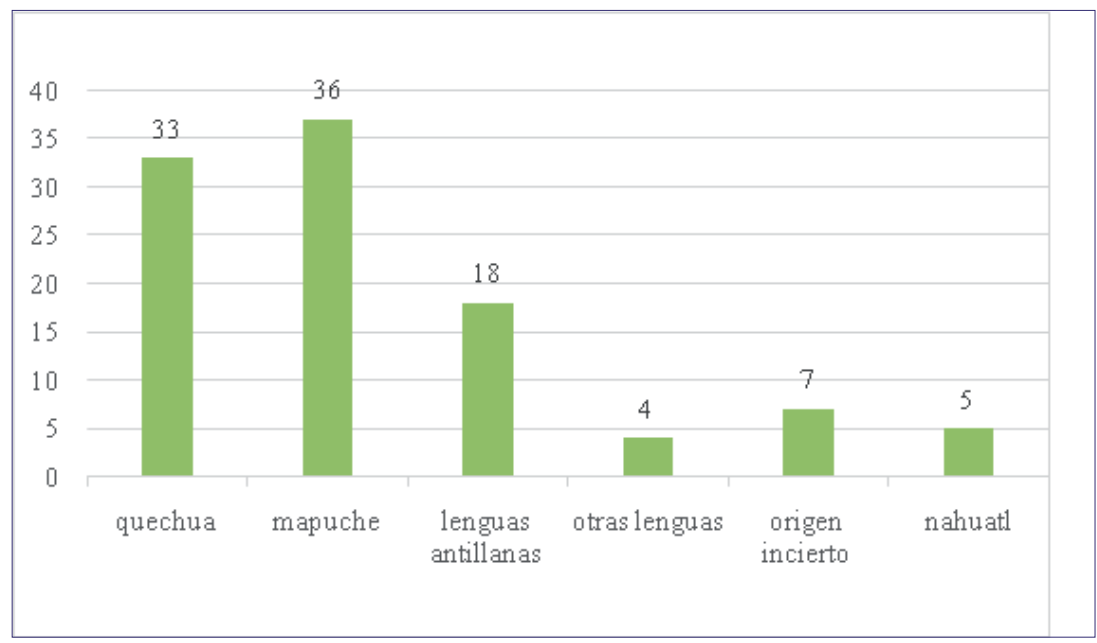

\section{A MODO DE CONCLUSIÓN}

Como explica Sánchez, no es "posible determinar con seguridad, en algunos casos, la forma original de las voces mapuches, por no haber quedado documentadas, o transcritas, de manera correcta" (2010: 252). Sin duda la grafía plantea un gran problema, pues cada autor escribe las palabras de forma diferente y esto dificulta a veces la identificación de los términos. Valgan para ilustrarlo tres palabras que aparecen en las diversas fuentes (en crónicas de Indias, en diccionarios modernos y antiguos o en fuentes actuales) con marcadas variaciones: culteu (queltehue, kültew, keltew, qlteu, kilteu); реисо (pewku, peucu, peuko) у peugu (pengus, pengu, pengo, peumo). Sánchez afirma que "tradicionalmente el léxico de origen mapuche no ha sido transcrito de manera adecuada. Los nombres suelen presentarse con alteraciones -incluso deformaciones- que no se condicen con la realidad fonológica de la lengua. Los errores que contienen las crónicas coloniales continúan repitiéndose. Ellos resultan comprensibles, pues sus autores no eran ni gramáticos ni lingüistas" (2010: 153). En cualquier caso, hemos conseguido identificar 36 mapuchismos en la obra de Ovalle. Para ello hemos consultado algunos vocabularios antiguos, como el de los misioneros 
jesuitas Luis de Valdivia (1684) y Andrés Febrés (1846); este último según las adiciones (y omisiones) del franciscano Antonio Hernández i Calzada. Alguna vez hemos acudido también al Diccionario de Antonio de Alcedo (1786-89) u otras fuentes, como por ejemplo la Historia general del reino de Chile, Flandes indiano (1674), de Diego de Rosales.

Doce de los mapuchismos aquí estudiados (carén, choñi, cona, degú, leupe, madi, malal, mallcagüe, mañegue, píngueda, taltal y ulmen) no se consignan en ninguna de las tres obras lexicográficas (DRAE-2014, DAm2010, DUECh-2010); mientras que tres de ellos aparecen solo en uno de los diccionarios: maloquear en DRAE-2014, rehue en DUECh-2010, chavalongo, como obsoleto, en DAm-2010. El DRAE-2014 recoge 21 voces mapuches, el DUECh-2010 recoge 20 y el DAm-2010 un total de 16. De alguna manera se podría sostener que es esa veintena de voces las que mantienen todavía vigencia y a ellas se podría añadir la voz degú, que no aparece en ninguno de los tres diccionarios. Las definiciones que ofrecen son parecidas y apenas ofrecen algún que otro matiz.

Como suele suceder en las crónicas de Indias, y en esto la de Ovalle no es una excepción, la mayor parte de los indoamericanismos son fitónimos y zoónimos, aunque llama la atención que en lo que se refiere a los mapuchismos, la mitad de ellos están relacionados con la cultura (choñi, cona, leupe, machi, macuñ, malal, mallcagüe, maloca, maloquear, rehue, toque, toqui, ulpo y ulmen) y la otra mitad con la flora y la fauna; de modo que la proporción es equilibrada.

Por último, cabe mencionar que respecto a la etimología, el DUECh-2010 es el único diccionario que consigna siempre el origen mapuche de las voces (la única excepción la constituye patagua), mientras que en el DRAE-2014 y el DAm-2010 aparece a veces la etimología, a veces una marca diatópica y a veces se señala simplemente que el objeto es originario de Chile (huingán: 'arbusto chileno'), o una combinación de los tres elementos.

\section{REFERENCIAS BIBLIOGRÁFICAS}

Academia Chilena de la Lengua. 2010. Diccionario de uso del español de Chile (DUECh-2010). Santiago de Chile: MN Editorial.

Alcedo, Antonio De. 1786-89. Diccionario geográfico-histórico de las Indias Occidentales. Madrid.

Alonso, Amado. 1947. Trueques de sibilantes en antiguo español. Nueva Revista de Filología Hispánica 1/1: 1-12. 
Alvar Ezquerra, Manuel. 1997. Vocabulario de indigenismos en las crónicas de Indias. Madrid: CSIC.

Álvarez Vita, Juan. 2009. Diccionario de Peruanismos. El habla castellana del Perú (DP2009). Lima: Universidad Alas Peruanas.

Asociación de Academias de la Lengua Española. 2010. Diccionario de americanismos (DAm-2010). Madrid: Santillana.

Bunster, CÉSAR. 1969. Algo acerca del trabajo realizado y algunas reflexiones sobre el valor literario de la obra. En Alonso de Ovalle. Histórica Relación del Reino de Chile y de las misiones y ministerios que ejercita en él la Compañía de Jesús. Santiago de Chile: Instituto de Literatura Chilena, 7-23.

Febrés, ANDrÉs. 1846. Diccionario hispano chileno, enriquecido y mejorado por el RP. Misionero Fr. Antonio Hernández. Santiago: Imprenta de los tribunales.

Hanish, Walter. 1976. El historiador Alonso de Ovalle. Caracas: Universidad Católica Andrés Bello.

Latcham, Ricardo A. 1955. Un clásico colonial: El Padre Alonso de Ovalle. Revista Bolívar 45: 853-864.

Lira Urquieta, Pedro. 1944. El Padre Alonso de Ovalle. El hombre, la obra. Santiago de Chile: Difusión Chilena.

Lozano, Pedro. 1733. Descripción Corographica del terreno, rios, árboles y animales de las dilatadissimas Provincias del gran Chaco, Gualamba: y de los ritos, y costumbres de las innumerables naciones bárbaras, e infieles, que la habitan... Córdoba de Tucumán. 1754. Historia de la Compañia de Jesús en la provincia del Paraguay. Madrid.

Prieto García-Seco, David. 2007. Notas sobre el Diccionario de la lengua (1917) de José Alemany y Bolufer. Revista de Lexicografia 13: 125-138.

Real Academia Española. 1726-1739. Diccionario de Autoridades. Madrid. 2014. Diccionario de la lengua española (DRAE-2014). Madrid: Espasa Calpe. 2001. Diccionario de la lengua española (DRAE-2001). Madrid: Espasa Calpe.

Rojo, Gulllermo. 2014. Análisis cuantitativo de las citas del Diccionario de Autoridades. Boletín de la Real Academia Española 94: 137-196.

Rosales, Diego De. 1989 [1674]. Historia general del reino de Chile, Flandes indiano. Santiago de Chile: Andrés Bello.

SÁnchez CABeZA, Gilberto. 2010. Los mapuchismos en el DRAE. Boletín de Filología XLV/ 2: $149-256$.

2005. La contribución léxica del mapudungun al español de Chile.UniverSOSRevista de Lenguas y Universos Culturales 2: 169-184.

VAldivia, Luis DE. 1887 [1684]. Arte y Gramática general de la lengua que corre en todo el Reyno de Chile, con un Vocabulario y Confessionario juntamente con la Doctrina Christiana, y Cathecismo del Concilio de Lima en Español, y dos traducciones del en la lengua de Chile. Sevilla.

Vial, Gonzalo. 2009. Chile. Cinco siglos de historia, vol. 1. Santiago: Zig-Zag. 